\title{
BMJ Open Performance of a novel ECG criterion for improving detection of left ventricular hypertrophy: a cross- sectional study in a general Chinese population
}

\author{
Yanli Chen, ${ }^{1}$ Guozhe Sun, ${ }^{1}$ Xiaofan Guo, ${ }^{1}$ Zhao Li, ${ }^{1}$ Guangxiao Li (i) , ${ }^{2}$ Ying Zhou, ${ }^{1}$ \\ Hongmei Yang, ${ }^{1}$ Shasha Yu, ${ }^{1}$ Liqiang Zheng (D) , ${ }^{3}$ Yingxian Sun (D) ${ }^{1}$
}

To cite: Chen Y, Sun G, Guo X, et al. Performance of a novel ECG criterion for improving detection of left ventricular hypertrophy: a cross-sectional study in a general Chinese population. BMJ Open 2021;11:e051172. doi:10.1136/ bmjopen-2021-051172

- Prepublication history and additional supplemental material for this paper are available online. To view these files, please visit the journal online (http://dx.doi.org/10.1136/ bmjopen-2021-051172).

Received 18 March 2021 Accepted 08 July 2021

A Check for updates

(C) Author(s) (or their employer(s)) 2021. Re-use permitted under CC BY-NC. No commercial re-use. See rights and permissions. Published by BMJ.

${ }^{1}$ Department of Cardiology, The First Hospital of China Medical University, Shenyang, Liaoning, China

${ }^{2}$ Department of Medical Record Management Center, The First Hospital of China Medical University, Shenyang, Liaoning, China

${ }^{3}$ Clinical Epidemiology, Library, Shengjing Hospital of China Medical University, Shenyang, Liaoning, China

Correspondence to Dr Yingxian Sun; yxsun@cmu.edu.cn

\section{ABSTRACT}

Objectives The sensitivity of ECG for detecting left ventricular hypertrophy (LVH) is low. The aim of this study was to explore a better ECG criterion for screening LVH in a large general Chinese population.

Design Case-control study.

Setting China Medical University in Shenyang, China. Participants All permanent residents in Dawa, Zhangwu and Liaoyang aged 35 years or older were invited. Participants with unqualified data, pacemaker rhythm, frequent premature ventricular beats, Wolff-ParkinsonWhite syndrome, complete bundle branch block, myocardial infarction or hypertrophic cardiomyopathy were excluded. A total of 10360 subjects (4630 males) were recruited.

Interventions A novel ECG criterion (Northeast China Rural Cardiovascular Health Study (NCRCHS)) composed of different ratios of maximum $R$ wave in lead $V_{5}$ or $V_{6}\left(R_{v 5 /}\right.$ $\left.{ }_{\mathrm{V} 6}\right)$, $S$ wave in lead $V_{3}\left(S_{V_{3}}\right)$ and $R$ wave in lead aVL $\left(R_{a v L}\right)$ was proposed and validated using multiple linear regression. Receiver-operating characteristic curves were used to compare the NCRCHS criterion with traditional criteria for LVH detection.

Results An optimised model $\left(15^{*} \mathrm{R}_{\mathrm{aVL}}+8^{*} \mathrm{~S}_{\mathrm{V} 3}+7^{*} \mathrm{R}_{\mathrm{v} 5 \mathrm{~N} 6}\right)$ was constructed $\left(R^{2} 0.192, p<0.001\right)$ with the cut-off values of $36.8 \mathrm{mV}$ for males and $26.1 \mathrm{mV}$ for females. The maximum area under the curve was obtained using the NCRCHS criterion (male $0.74,95 \% \mathrm{Cl} 0.73$ to 0.75 ; female 0.73 , $95 \% \mathrm{Cl} 0.72$ to 0.75 ), followed by Cornell voltage criterion, Sokolow-Lyon criterion, Peguero-Lo Presti criterion, multiethnic study of atherosclerosis (MESA)-specific criterion and Syst-Eur voltage criterion. Compared with the Cornell voltage criterion, the NCRCHS criterion had a significantly higher sensitivity for detecting LVH at the same level of specificity $(p<0.05)$.

Conclusions The NCRCHS criterion significantly improved sensitivity for LVH detection in a general Chinese population, with cut-off values of 36.8 and $26.1 \mathrm{mV}$ for males and females, respectively. This criterion can detect LVH earlier and better and may prevent subsequent cardiovascular diseases.

\section{Strengths and limitations of this study}

- A large sample of 10360 individuals from a general Chinese population was studied.

- To the best of our knowledge, this is the first study to investigate a new ECG method for predicting left ventricular hypertrophy in a general Chinese population.

- The present study proposed a new ECG criterion (Northeast China Rural Cardiovascular Health Study (NCRCHS) criterion) with higher sensitivity than traditional criteria.

- The NCRCHS criterion needs to be validated in other populations.

\section{INTRODUCTION}

Left ventricular hypertrophy (LVH) has been shown to be an important predictor of cardiovascular events and mortality, especially in patients with hypertension. ${ }^{1-3}$ ECG is commonly used as the first-line method for $\mathrm{LVH}$ detection due to its convenience and cost-effectiveness. Numerous ECG criteria have been established for the diagnosis of LVH. However, low sensitivity restricts the applications of these methods in clinical practice. A better screening method for $\mathrm{LVH}$ with an improved detection ability of LVH should be explored.

The Cornell voltage criterion, reported to be the best criterion with the highest predictive ability, was constructed using the $\mathrm{R}$ wave in lead aVL $\left(\mathrm{R}_{\mathrm{aVL}}\right)$ and $\mathrm{S}$ or QS complex in lead $V_{3}\left(S_{\mathrm{V} 3}\right)$. The $R$ wave in lead $V_{5}$ or $V_{6}$ is the main component of the Sokolow-Lyon criterion, ${ }^{4}$ which is directed towards the cardiac depolarisation vector. It is considered to represent the value of the cardiac electrical activity in the anterior left of the horizontal plane (figure 1). ${ }^{5}$ The sum of 


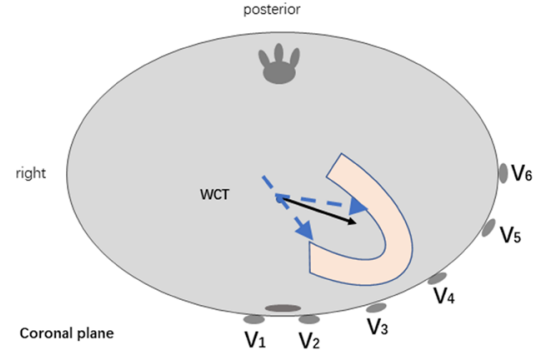

A

(1)

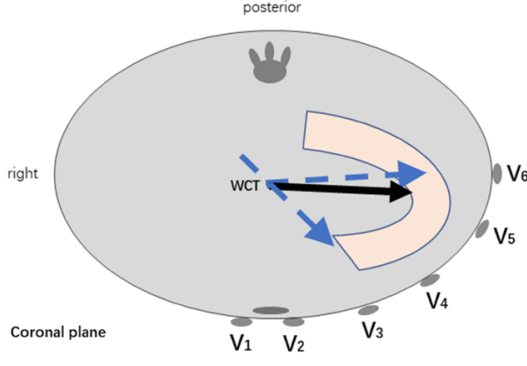

B

(1)

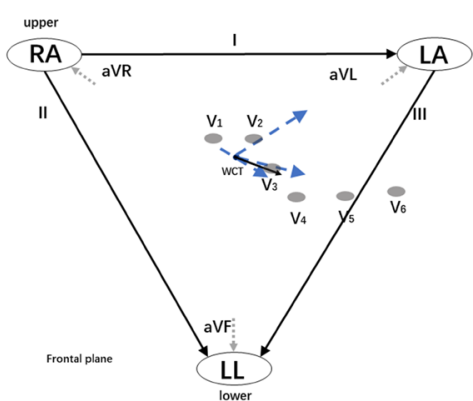

(2)

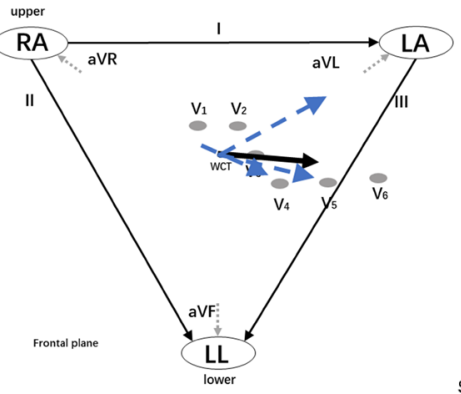

(2)

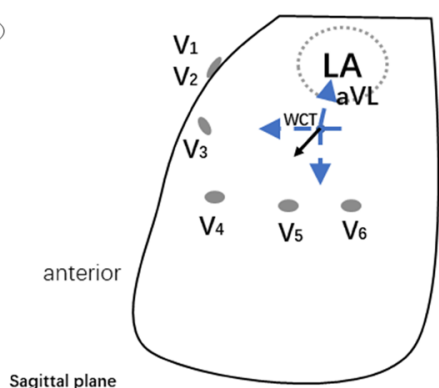

(3)

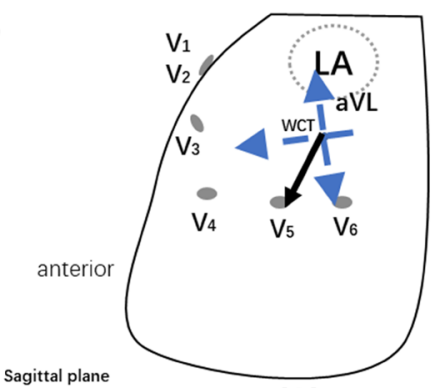

(3)

Figure 1 Diagram for vector change in left ventricular hypertrophy. (A) Normal vector for non-hypertrophic heart in coronal plane (1), frontal plane (2) and sagittal plane (3). (B) Vector changes in hypertrophic heart in coronal plane (1), frontal plane (2) and sagittal plane (3), WCT and cardiac vector became more posteriorly oriented. Black arrow indicates whole cardiac vector, and blue arrow shows vector for leads $-S_{v_{3}}, R_{v 5 N_{6}}$ or $R_{a v L}$. LA, left arm; LL, left leg; RA, right arm; WCT, Wilson Central Terminal.

$\mathrm{R}_{\mathrm{v} 5 / \mathrm{V} 6}$ and traditional Cornell voltage covered threedimensional ECG amplitude changes and thus facilitated a better evaluation of three-dimensional modifications in the hypertrophic ventricle. A novel ECG expression $\left(\beta_{1} R_{\mathrm{aVL}}+\beta_{2} \mathrm{~S}_{\mathrm{v} 3}+\beta_{3} \mathrm{R}_{\mathrm{v} 5 / \mathrm{V} 6}\right)$ was based on the multiple linear regression analysis of $\mathrm{R}_{\mathrm{aVL}}, \mathrm{S}_{\mathrm{v} 3}$ and $\mathrm{R}_{\mathrm{v} 5 / \mathrm{v} 6}$ against the left ventricular mass index (LVMI). The aims of the present study were to evaluate the diagnostic performance of the newly proposed Northeast China Rural Cardiovascular Health Study (NCRCHS) criterion $\left(\beta_{1} R_{\mathrm{avL}}+\beta_{2} \mathrm{~S}_{\mathrm{v} 3}+\beta_{3} \mathrm{R}_{\mathrm{v} 5 / \mathrm{V} 6}\right)$ and to further determine its gender-specific cut-off values in a large general Chinese population.

\section{MATERIALS AND METHODS \\ Study population}

Data were acquired from a previously published crosssectional study known as the NCRCHS. ${ }^{6}$ Briefly, a multistage, randomly stratified, cluster-sampling study was conducted between January 2013 and August 2013 in three counties (Dawa, Zhangwu and Liaoyang) and 26 nearby rural villages $(n=14016)$ of Liaoning Province in participants older than 35 years. This was a retrospective study to investigate a better ECG standard for LVH prediction using NCRCHS data. Subjects with missing data and/ or poor echocardiographic or ECG quality were excluded from further analysis. Other exclusion criteria for ECG or echocardiography were as follows: (1) pacemaker rhythm or frequent premature ventricular beats $(\geq 3$ beats $/ \mathrm{min})$; (2) complete left/right bundle branch block; (3) WolffParkinson-White syndrome; (4) self-reported history of myocardial infarction, or subjects with presentations of myocardial infarction in ECG and asynergy of left ventricular wall motion in echocardiography; and (5) hypertrophic cardiomyopathy in echocardiography.

This study was undertaken in accordance with the Second Helsinki Declaration. Written informed consent was obtained from all subjects prior to their participation in the study.

\section{Data collection}

Data collection was conducted using a standardised questionnaire. Height, weight and waist circumference were measured by well-trained technicians following a standard protocol. Body mass index (BMI) was calculated from weight and height, which were measured to the nearest $0.1 \mathrm{~kg}$ and $0.1 \mathrm{~cm}$, respectively. Lipid profiles, blood routine tests, and creatinine, uric acid and fasting blood glucose (FBG) levels were enzymatically analysed on an Olympus AU640 auto-analyser (Olympus, Kobe, Japan). Blood pressure was measured according to the American Heart Association guidelines ${ }^{7}$ with a HEM-907 Omron sphygmomanometer (Omron Healthcare, Kyoto, Japan). The average value of three measurements was used in the final analyses. Hypertension was defined as systolic blood pressure $\geq 140 \mathrm{mmHg}$ or diastolic blood pressure $\geq 90 \mathrm{~mm} \mathrm{Hg}$, using self-reported history of hypertension, or by the use of antihypertensive medications.

\section{Electrocardiographic criteria for LVH}

Twelve-lead resting ECGs for all participants were recorded by well-trained cardiologists with a sweep speed of $25 \mathrm{~mm} / \mathrm{s}$ and calibration set at $10 \mathrm{~mm} / \mathrm{mV}$ (MAC 5500; GE Healthcare). The Marquette 12SL ECG analysis 
Table 1 Traditional electrocardiographic criteria for comparison

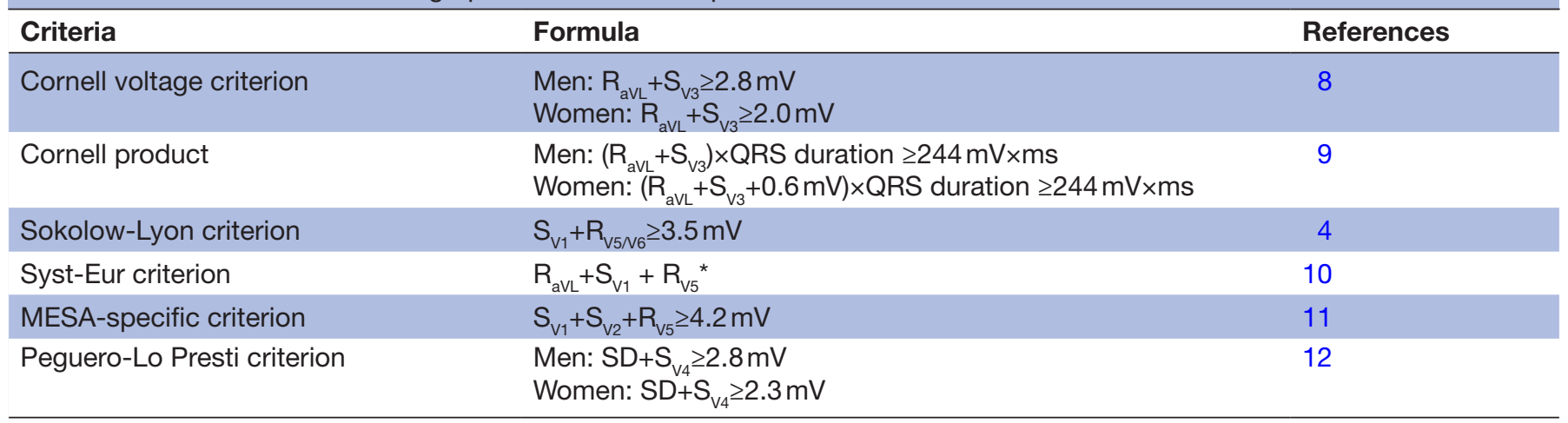

${ }^{*}$ No diagnostic cut-off values were reported for Syst-Eur criterion.

MESA, multi-ethnic study of atherosclerosis; SD, deepest $S$ wave in any lead.

program (MUSE; V.7.0.0; GE Healthcare) was used for digital ECG recording, interpretation, storage and analysis. All ECG criteria for LVH prediction were calculated using the MUSE computer-generated algorithm for ECG. Individual leads were analysed by measuring the tallest $\mathrm{R}$ wave and the deepest $\mathrm{S}$ or QS complex in all of the precordial and limb leads using the PR segment as baseline. The QRS duration was defined as the time from the beginning of the $Q$ wave to the end of the $S$ wave. Supplemental figure represents the measuring method for $\mathrm{R}_{\mathrm{aVL}}, \mathrm{S}_{\mathrm{v} 3}$ and $\mathrm{R}_{\mathrm{V} 5 / \mathrm{V} 6}$ on an ECG. The efficacy of the novel NCRCHS criterion was compared with that of other traditional criteria: Cornell voltage criterion, ${ }^{8}$ Cornell product, ${ }^{9}$ Sokolow-Lyon criterion, ${ }^{4}$ Syst-Eur criterion, ${ }^{10}$ multi-ethnic study of atherosclerosis (MESA)-specific criterion $^{11}$ and Peguero-Lo Presti criterion ${ }^{12}$ (table 1).

\section{Echocardiography}

Echocardiograms were carried out on the same day as ECG using standard, commercially available Doppler echocardiographs (Vivid; GE Healthcare) with a $3.0 \mathrm{MHz}$ transducer. The diastolic interventricular septal thickness (IVSTd), diastolic posterior wall thickness (PWTd), left ventricular end-diastolic diameter (LVEDD), left ventricular end-systolic diameter (LVESD) and left ventricular ejection fraction (LVEF) were measured according to the recommendations of the American Society of Echocardiography. ${ }^{13}{ }^{14}$ A modified Simpson method was used to obtain the LVEF. ${ }^{13}$ Left ventricular mass (LVM) was calculated using the Devereux formula ${ }^{15}$ as follows: $0.8 \times 1.04 \times\left((\text { IVSTd }+ \text { LVEDD }+ \text { PWTd })^{3}-(\text { LVEDD })^{3}\right)+0.6$, and divided by body surface area to calculate LVMI, the gold standard for diagnosing LVH in this study. The body surface area was calculated using the Stevenson formula as follows: $0.0061 \times$ height $(\mathrm{cm})+0.0128 \times w t(\mathrm{~kg})-0.1529$. Finally, LVH was defined as LVMI $>115 \mathrm{~g} / \mathrm{m}^{2}$ in males or $>95 \mathrm{~g} / \mathrm{m}^{2}$ in females. ${ }^{13}$ To further confirm the LVH findings, LVH was also defined based on the standard of de Simone (LVM divided by height ${ }^{2.7}$ ). ${ }^{16}$

\section{Statistical analysis}

Continuous variables were expressed as means \pm SD. Categorical variables were represented as frequencies or percentages. Differences between characteristics of subjects with and without echocardiographic LVH (echo-LVH) were examined using Student's t-test or $\chi^{2}$ test accordingly. Multiple linear regression with robust SE was used to assess the relationships between electrocardiographic indices and LVMI to construct the formula for the NCRCHS criterion. All ECGs constructing the regression model were used for the following comparison between models. Receiveroperating characteristic curves (ROCs) were plotted to compare the performance of each criterion, and the respective area under the curve (AUC) was assessed using the DeLong's method. ${ }^{17}$ Values with $90 \%$ specificity were used as the cut-off values for the NCRCHS criterion. Subjects with missing anthropometric details were excluded. Given the LVMI standard, sensitivity, specificity, positive predictive value (PPV), negative predictive value (NPV) and $\mathrm{F}_{1}$ score were determined using the following formulas:

$\mathrm{PPV}=\mathrm{TP} / \mathrm{TP}+\mathrm{FP}, \quad \mathrm{NPV}=\mathrm{TN} / \mathrm{TN}+\mathrm{FN} ; \mathrm{F}_{1}$ score $=2 \mathrm{TP} /$ $(2 \mathrm{TP}+\mathrm{FP}+\mathrm{FN})$, where $\mathrm{TP}$ is the number of true positives, FP is the number of false positives, TN is the number of true negatives and $\mathrm{FN}$ is the number of false negatives.

Statistical analyses were performed using Statistical Package for the Social Sciences (SPSS) V.22.0 (SPSS) and MedCalc V.18.11.3 (MedCalc Software bvba, Ostend, Belgium). All results were reported as percentages with their corresponding $95 \%$ CI. A two-tailed $\mathrm{p}<0.05$ was considered statistically significant.

\section{Patient and public involvement}

Patients or the public were not involved in the design, conduct, reporting, or dissemination plans of the present research.

\section{RESULTS}

\section{Baseline clinical characteristics}

The inclusion process for study participants is described in figure 2. After filtering patients based on the exclusion 
11,956 participants

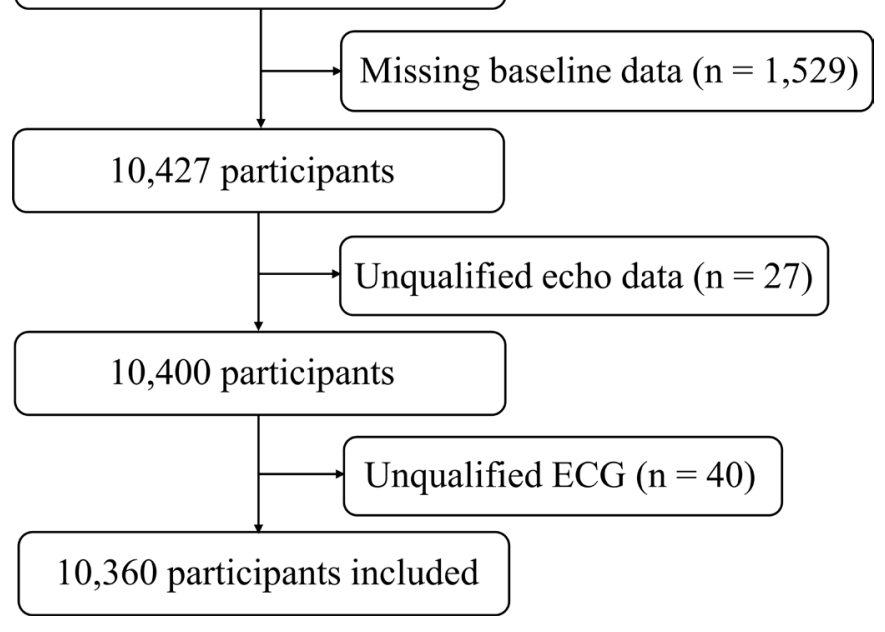

Figure 2 Flow chart for participant selection process.

criteria, a total of 10360 participants (mean age: $53.6 \pm 10.6$ years, 4630 males) remained for further analysis. Baseline characteristics of the target population are shown in table 2. There were 1270 (12.3\%) subjects showing echocardiographic LVH. Compared with the non-LVH group, subjects with echo-LVH had a significantly higher serum level of total cholesterol, low-density lipoprotein cholesterol, FBG, creatinine, uric acid and blood sodium (all $\mathrm{p}<0.05)$. In addition, significantly higher BMI was found in LVH subjects $(\mathrm{p}<0.001)$.
Determination of expression formula for NCRCHS criterion

Due to the three-dimensional relationships among leads $\mathrm{R}_{\mathrm{aVL}}, \mathrm{S}_{\mathrm{v} 3}$ and $\mathrm{R}_{\mathrm{v} 5 / \mathrm{V} 6}$ (figure 1 ), an optimised linear regression model $\left(R^{2} 0.192, p<0.001\right)$ was constructed as follows:

$\mathrm{LVMI}=60.25+15.35^{*} \mathrm{R}_{\mathrm{aVL}}+7.55^{*} \mathrm{~S}_{\mathrm{v} 3}+6.67^{*} \mathrm{R}_{\mathrm{v} 5 / \mathrm{V} 6}$

The variance inflation factor and the Durbin-Watson values of this model showed no multicollinearity between the variables $\left(\mathrm{R}_{\mathrm{aVL}}, \mathrm{S}_{\mathrm{V} 3}\right.$ and $\left.\mathrm{R}_{\mathrm{V} 5 / \mathrm{V} 6}\right)$. The NCRCHS criterion was defined as ' $15^{*} \mathrm{R}_{\mathrm{aVL}}+8{ }^{*} \mathrm{~S}_{\mathrm{v} 3}+7^{*} \mathrm{R}_{\mathrm{v} 5 / \mathrm{V} 6}$ ' without a constant.

\section{Diagnostic performance of electrocardiographic LVH (ECG- LVH) measured against echo-LVH}

AUCs for all ECG-LVH criteria are shown in table 3. According to the LVMI standard, the $\mathrm{R}$ wave in lead $\mathrm{V}_{5}$ and lead I had the highest AUC for one-lead measurements for both males and females (both $\mathrm{p}<0.001$ ). Two-lead ECG-LVH criteria, including Cornell voltage, Sokolow-Lyon criterion and Peguero-Lo Presti criterion, resulted in a series of AUCs ranging from 0.65 to 0.69 for males and from 0.64 to 0.70 for females (all $\mathrm{p}<0.001$ ). The Cornell voltage criterion performed best in both single-lead and two-lead measurements.

For the three-lead measurements, MESA-specific ECG$\mathrm{LVH}$ criterion $\left(\mathrm{Sv}_{1}+\mathrm{Sv}_{2}+\mathrm{Rv}_{5}\right)$ and Syst-Eur voltage criterion $\left(\mathrm{R}_{\mathrm{aVL}}+\mathrm{Sv}_{1}+\mathrm{Rv}_{5}\right)$ were included for comparison. In the present study, the NCRCHS criterion performed significantly better than the other two-lead or three-lead measurements, with AUCs of 0.74 for males and 0.73 for females (both $\mathrm{p}<0.001$ ). The NCRCHS product, where

\begin{tabular}{|c|c|c|c|c|}
\hline Baseline characteristics & $\begin{array}{l}\text { Overall } \\
(N=10360)\end{array}$ & $\begin{array}{l}\text { LVH } \\
(n=1270)\end{array}$ & $\begin{array}{l}\text { Non-LVH } \\
(\mathrm{n}=9090)\end{array}$ & P value* \\
\hline Male, n (\%) & $4630(44.7)$ & $418(32.9)$ & 4212 (46.3) & $<0.001$ \\
\hline Hypertension, n (\%) & $5226(50.4)$ & $1012(79.7)$ & $4214(46.4)$ & $<0.001$ \\
\hline DBP (mm Hg) & $81.9 \pm 11.7$ & $87.5 \pm 14.1$ & $81.1 \pm 11.1$ & $<0.001$ \\
\hline FBG (mmol/L) & $5.9 \pm 1.6$ & $6.1 \pm 1.7$ & $5.9 \pm 1.6$ & $<0.001$ \\
\hline $\mathrm{TC}(\mathrm{mmol} / \mathrm{L})$ & $5.2 \pm 1.1$ & $5.5 \pm 1.1$ & $5.2 \pm 1.1$ & $<0.001$ \\
\hline LDL-C (mmol/L) & $2.9 \pm 0.8$ & $3.1 \pm 0.9$ & $2.9 \pm 0.8$ & $<0.001$ \\
\hline $\operatorname{LVM}(\mathrm{g})$ & $137.6 \pm 35.7$ & $189.8 \pm 42.7$ & $130.4 \pm 27.6$ & $<0.001$ \\
\hline LVMI $\left(\mathrm{g} / \mathrm{m}^{2}\right)$ & 83.6ะ19.1 & $117.6 \pm 20.1$ & $78.8 \pm 13.2$ & $<0.001$ \\
\hline LVEF (\%) & $63.1 \pm 3.8$ & $62.4 \pm 4.6$ & $63.2 \pm 3.7$ & $<0.001$ \\
\hline
\end{tabular}

*Indicates examination of differences between participants with and without LVH.

BMI, body mass index; DBP, diastolic blood pressure; FBG, fasting blood glucose; HDL-C, high-density lipoprotein cholesterol; LDL-C, lowdensity lipoprotein cholesterol; LVEF, left ventricular ejection fraction; LVH, left ventricular hypertrophy; LVM, left ventricular mass; LVMI, left ventricular mass index; SBP, systolic blood pressure; TC, total cholesterol. 
Table 3 Area under the ROC curves for different electrocardiographic criteria used for predicting left ventricular hypertrophy

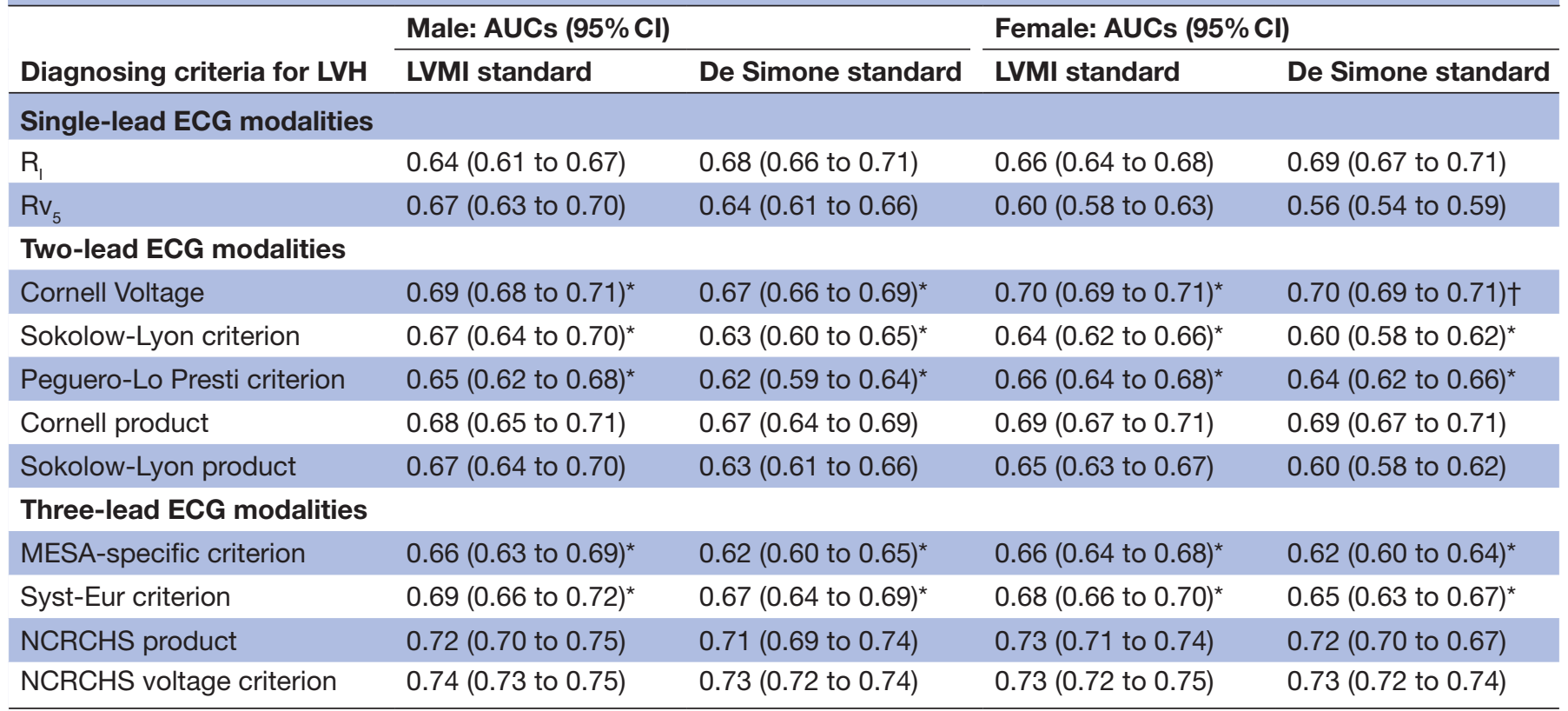

The single-lead criterion with AUCs $<0.5$ was not listed.

*Indicates $p<0.01$ in comparison to the NCRCHS voltage criterion.

tIndicates $\mathrm{p}<0.05$ in comparison to the NCRCHS criterion.

AUCs, area under the curves; LVH, left ventricular hypertrophy; LVMI, left ventricular mass index; MESA, multi-ethnic study of atherosclerosis; NCRCHS, Northeast China Rural Cardiovascular Health Study; ROC, receiver-operating characteristic curve.

the NCRCHS criterion voltage value and QRS duration were multiplied, did not improve diagnostic ability compared with the NCRCHS criterion.

Accordingly, ROC curves were plotted to explore the NCRCHS criterion's best performance based on LVMI standard (figure $3 \mathrm{~A}$ and $\mathrm{B}$ ) and de Simone standard (figure 3C and D). Sensitivity, specificity, PPV, NPV and $\mathrm{F}_{1}$ score for NCRCHS voltage criterion and traditional criteria are listed in online supplemental table 1.

\section{Comparison of NCRCHS criterion and Cornell voltage criterion}

In order to compare the performance of the NCRCHS criterion with that of Cornell criterion for detecting $\mathrm{LVH}$, sensitivities and specificities were calculated for males and females at the cut-off point or at the $90 \%$ level of specificity (online supplemental table 2 ). The sensitivity for the NCRCHS criterion was significantly higher than that for the Cornell voltage criterion using the DeLong's method at the same level of specificity (all $\mathrm{p}<0.05$ ). Based on the previous studies, ${ }^{8}$ sex-specific cut-off values for the NCRCH criterion were set at the $90 \%$ level of specificity (males: $36.8 \mathrm{mV}$, females: $26.1 \mathrm{mV}$ ).

\section{DISCUSSION}

\section{Principal study findings}

The main findings of the present study were as follows: a novel ECG criterion (NCRCHS criterion $=15^{*} \mathrm{R}_{\mathrm{aVL}}+8^{*} \mathrm{~S}_{\mathrm{v} 3}+7^{*} \mathrm{R}_{\mathrm{v} 5 / \mathrm{V} 6}$ ) to predict $\mathrm{LVH}$ was proposed and maximum AUCs of 0.74 for males and 0.73 for females were obtained using the NCRCHS criterion; sensitivity and specificity of the NCRCHS criterion were $90.0 \%$ and $36.0 \%$, respectively, and sex-specific cut-off values for the NCRCHS criterion were $\geq 36.8 \mathrm{mV}$ for males and $\geq 26.1 \mathrm{mV}$ for females.

Due to its conical shape, a left hypertrophic ventricle causes different vector changes in different directions, resulting in three-dimensional ECG modifications (figure 1). The $\mathrm{R}$ wave in lead $\mathrm{V}_{5}$ or $\mathrm{V}_{6}$ is directed towards the cardiac depolarisation vector and is considered to represent the value of the cardiac electrical activity in the anterior left of the horizontal plane. ${ }^{5} \mathrm{~S}$ wave amplitudes in $\mathrm{V}_{3}$ and $\mathrm{V}_{4}$ are believed to reflect the depolarisation of the posterior ventricular myocardium and thus change in accordance with more posteriorly oriented chamber in case of hypertrophy. ${ }^{8}{ }^{18-20}$ Since the direction of the $\mathrm{S}$ wave in $\mathrm{V}_{4}$ is very similar to the opposite direction of the $R$ wave in lead $V_{5}$, and the direction of lead $V_{5}$ or $\mathrm{V}_{6}$ represents the main depolarisation direction of the heart, only the $\mathrm{S}$ wave amplitude in $\mathrm{V}_{3}$ was included in the construction of the NCRCHS voltage. The direction of $R_{a V L}$ was nearly perpendicular to the plane defined by $\mathrm{S}_{\mathrm{v} 3}$ and $\mathrm{R}_{\mathrm{V} 5 / \mathrm{V} 6}$. $\mathrm{R}_{\mathrm{aVL}}$ voltage measured in the hypertrophied heart ${ }^{821}$ was tightly correlated with LVMI. ${ }^{22-24} R_{\text {aVL }}$ alone or in combination with N-terminal B-type natriuretic peptide had a better predictive value for cardiovascular risk than echo alone. ${ }^{23}$ Although the $\mathrm{R}$ wave in lead I had the best performance in single-lead ECG prediction, it was not used to construct the NCRCHS criterion because wave amplitudes in bipolar limb leads (leads I, II and III) are easily influenced by altering the 

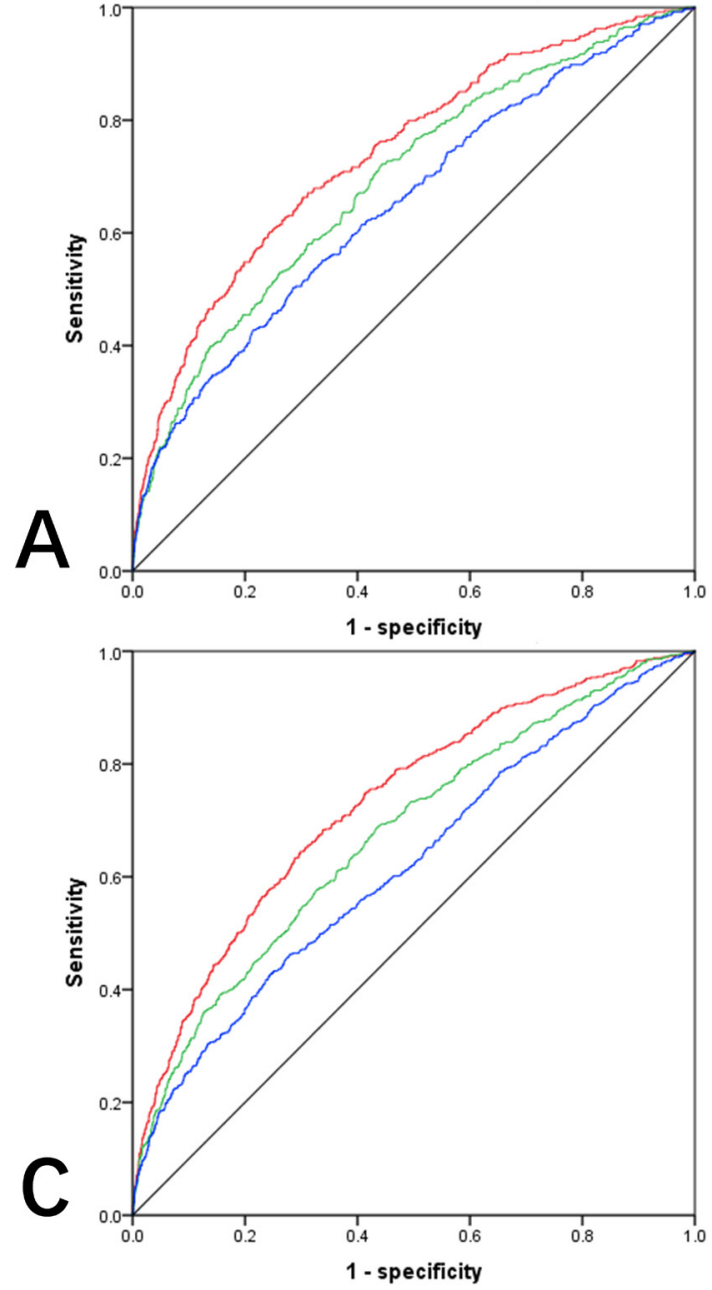

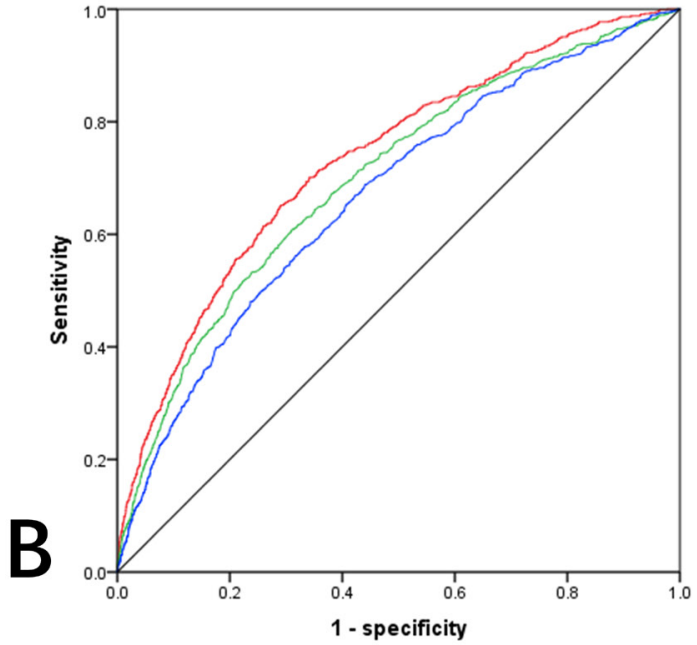

Source of the curve

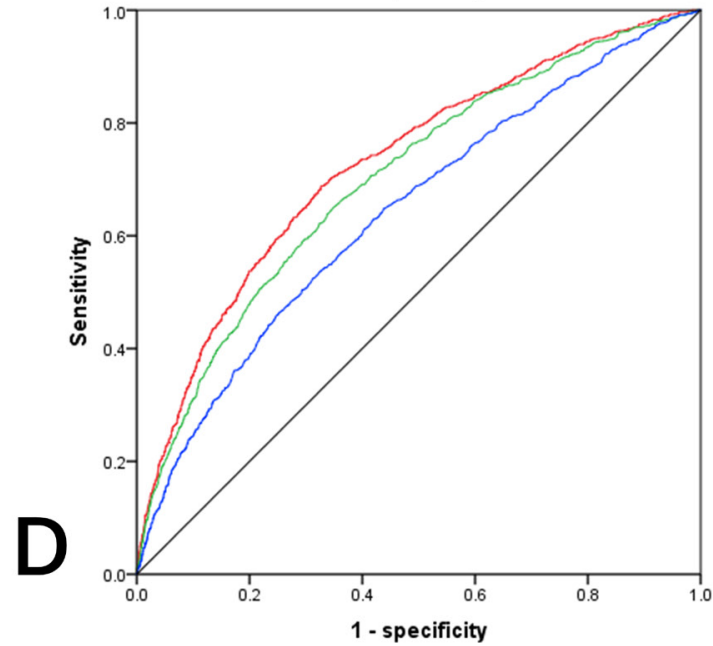

Figure 3 ROC curves for all ECG indices for predicting LVH. ROC curves of males (A) and females (B) under the LVMI standard, ROC curves for males (C) and females (D) under the de Simone standard. LVH, left ventricular hypertrophy; LVMI, left ventricular mass index; NCRCHS, Northeast China Rural Cardiovascular Health Study; ROC, receiver operating characteristic curve.

lead position. ${ }^{26}$ As a result, three-dimensional changes in ECG voltage in $\mathrm{S}_{\mathrm{v} 3}, \mathrm{R}_{\mathrm{v} 5 / \mathrm{v} 6}$ and $\mathrm{R}_{\mathrm{avL}}$ were included in the NCRCHS criterion. Due to the different changes in hypertrophic heart vectors, the combination of different $\mathrm{R}$ or $\mathrm{S}$ wave ratios for three constituent leads contributes to the superiority of this criterion.

\section{Strengths and limitations}

Many ECG indices for LVH detection have been reported. ${ }^{4-12}$ New strategies based on non-ECG participants' characteristics and ECG variables have been reported to improve LVH prediction ability. ${ }^{11}$ However, the NCRCHS criterion is much easier to automatically calculate using an electrocardiographic machine or by doctors in clinical practice. The present study referred to a large sample of 10360 individuals. To the best of our knowledge, this is the first study to investigate a new ECG criterion for predicting LVH in Chinese population. In addition, the sum of different scales (instead of same ratios) of three ECG leads representing conical changes in ECG vectors in a left hypertrophic ventricle may contribute to the superiority of the NCRCHS criterion.
This study has limitations that should be considered. First, all ECGs included in the construction of the regression model were used for the comparison and no validation dataset was included. Additional data from other populations are needed for validation of the NCRCHS criterion. Second, relationships between the NCRCHS criterion and other LVH detection methods, such as cardiac MRI, should be explored. Cardiac MRI is a relatively reliable standard for assessing LVM, but it is not a generally available examination in Chinese rural areas and MRI for large population samples is not an option. More data are needed to validate the NCRCHS criterion.

\section{Study implications}

LVH is a well-known risk factor for heart failure, arrhythmia, sudden death and kidney disease. The occurrence of LVH strongly predicts future cardiovascular morbidity and mortality. ${ }^{27-30}$ Furthermore, electrical LVH with ECG has separate associations with CVD outcomes independent of anatomic LVH. ${ }^{31}$ ECG evidence for LVH has been incorporated into a cardiovascular disease (CVD) risk score to reduce the incidence of secondary 
cardiovascular events. ${ }^{32}$ The novel NCRCHS ECG voltage criterion is composed of leads in different directions and thereby significantly improves LVH prediction. Better diagnostic ability helps the NCRCHS criterion to detect LVH earlier and with higher precision. LVH is a modifiable risk factor for CVD and mortality. ${ }^{33}{ }^{34} \mathrm{LVH}$ detection with higher sensitivity can potentially create more awareness of complications, encourage primary prevention of CVDs and improve clinical outcomes. ${ }^{35} 36$

ECG is the simplest, most economical and convenient method of screening LVH. It is the first-line screening method for LVH in large population studies. Because ethnic groups differ in anthropometric measures that correlate with heart size, ${ }^{37}$ ethnic-specific criteria for LVH may be warranted. Prior studies have shown the same ECG criteria with different sensitivity and specificity in different populations. ${ }^{12}{ }^{38}$ Until now, no specific criterion for LVH prediction has been reported for the Chinese population. The present study included a large sample of 10360 individuals from a general Chinese population and determined a simple and optimal model to screen for LVH. The NCRCHS voltage criterion may represent a better method for LVH prediction in a Chinese population than other traditional criteria developed based on other populations.

\section{Unanswered questions and future research}

ECG remains the simplest and most important method for LVH detection. It also has an important role in the primary care system and preventive medicine. $\mathrm{LVH}$, as a sign of the target organ damage, should be evaluated and intervened with early in patients with hypertension. Echocardiography is another commonly used method to detect LVH. However, it has significant interobserver variability ${ }^{39}$ and is affected by ultrasonic section and body shape. It is not universally recommended for adults to assess LVH by means of echocardiography or MRI during evaluation and management of hypertension. ${ }^{40}$ The NCRCHS criterion with higher sensitivity for predicting LVH will improve the management of hypertension. Whether the NCRCHS criterion has a better ability to predict LVH than traditional criteria in other races or in other Chinese populations remains unclear.

ECG evidence for LVH is incorporated in risk assessment for CVD and can improve CVD risk prediction. ${ }^{35} 41$ Individualised risk reduction plans are needed for patients with different CVD risk scores. Because the prevalence of LVH and incidence of morbid events vary depending on the threshold selected for the ECG criteria, ${ }^{42-46}$ it is advisable to determine if thresholds obtained from the general population apply to patients with hypertension. Sensitivity requirements for detecting $\mathrm{LVH}$ in different populations also vary. Different cut-off values for each ECG criterion result in different sensitivity and specificity. Therefore, specific cut-off values for patients with a different cardiovascular risk are reasonable. Further research is needed to investigate cardiovascular outcomes associated with the
NCRCHS criterion and its specific cut-off values among populations with a different risk score.

\section{CONCLUSIONS}

The proposed NCRCHS ECG criterion $\left(15^{*} \mathrm{R}_{\mathrm{aVL}}+8^{*} \mathrm{~S}_{\mathrm{v} 3}+7^{*} \mathrm{R}_{\mathrm{V} 5 / \mathrm{V} 6}\right)$ significantly improved the diagnostic ability for LVH in a general Chinese cohort, with the cut-off values of $\geq 36.8$ and $\geq 26.1 \mathrm{mV}$ for males and females, respectively. This criterion can be used clinically to ensure better and earlier LVH detection and treatment in order to prevent subsequent cardiovascular outcomes.

Contributors YC contributed to the conception or design of the work and wrote the manuscript. YC, LZ and GL performed the data analyses. GS and XG critically revised the manuscript. YS directed the study and obtained the funding. ZL, YZ, $\mathrm{HY}$ and SY took part in data collection. All gave final approval and agreed to be accountable for all aspects of work ensuring integrity and accuracy.

Funding The authors thank the National Key Research and Development Program of China (No. 2017YFC1307600).

Competing interests Professor YS obtained funding from the National Key Research and Development Program of China (No. 2017YFC1307600).

Patient consent for publication Not required.

Ethics approval The study was approved by the institutional ethics review committee of the First Affiliated Hospital of China Medical University (AF-SOP-07-

1.0-01). All patients were given the opportunity to withdraw their participation using an opt-out procedure.

Provenance and peer review Not commissioned; externally peer reviewed.

Data availability statement Data are available upon reasonable request. Deidentified individual participant data are available from the corresponding author ( yxsun@cmu.edu.cn) upon reasonable request and with permission of the NCRCHS study group.

Supplemental material This content has been supplied by the author(s). It has not been vetted by BMJ Publishing Group Limited (BMJ) and may not have been peer-reviewed. Any opinions or recommendations discussed are solely those of the author(s) and are not endorsed by BMJ. BMJ disclaims all liability and responsibility arising from any reliance placed on the content. Where the content includes any translated material, BMJ does not warrant the accuracy and reliability of the translations (including but not limited to local regulations, clinical guidelines, terminology, drug names and drug dosages), and is not responsible for any error and/or omissions arising from translation and adaptation or otherwise.

Open access This is an open access article distributed in accordance with the Creative Commons Attribution Non Commercial (CC BY-NC 4.0) license, which permits others to distribute, remix, adapt, build upon this work non-commercially, and license their derivative works on different terms, provided the original work is properly cited, appropriate credit is given, any changes made indicated, and the use is non-commercial. See: http://creativecommons.org/licenses/by-nc/4.0/.

\section{ORCID iDs}

Guangxiao Li http://orcid.org/0000-0003-0318-3490

Liqiang Zheng http://orcid.org/0000-0003-0101-9398

Yingxian Sun http://orcid.org/0000-0002-1961-899X

\section{REFERENCES}

1 Levy D, Garrison RJ, Savage DD, et al. Prognostic implications of echocardiographically determined left ventricular mass in the Framingham heart study. N Engl J Med 1990;322:1561-6.

2 Narayanan K, Reinier K, Teodorescu C, et al. Electrocardiographic versus echocardiographic left ventricular hypertrophy and sudden cardiac arrest in the community. Heart Rhythm 2014;11:1040-6.

3 Ahmad MI, Mujtaba M, Anees MA, et al. Interrelation between electrocardiographic left atrial abnormality, left ventricular hypertrophy, and mortality in participants with hypertension. Am J Cardiol 2019;124:886-91. 
4 Sokolow M, Lyon TP. The ventricular complex in left ventricular hypertrophy as obtained by unipolar precordial and limb leads. $A m$ Heart $J$ 1949;37:161-86.

5 Romhilt DW, Bove KE, Norris RJ, et al. A critical appraisal of the electrocardiographic criteria for the diagnosis of left ventricular hypertrophy. Circulation 1969;40:185-96.

6 Sun G-Z, Guo L, Wang X-Z, et al. Prevalence of atrial fibrillation and its risk factors in rural China: a cross-sectional study. Int J Cardiol 2015;182:13-17.

7 Chobanian AV, Bakris GL, Black HR. Blood Institute joint National Committee on prevention de, treatment of high blood P, National high blood pressure education program coordinating $\mathrm{C}$ : the seventh report of the joint National Committee on prevention, detection, evaluation, and treatment of high blood pressure: the JNC 7 report. JAMA 2003:289:2560-72.

8 Casale PN, Devereux RB, Kligfield P, et al. Electrocardiographic detection of left ventricular hypertrophy: development and prospective validation of improved criteria. J Am Coll Cardio 1985;6:572-80.

9 Molloy TJ, Okin PM, Devereux RB, et al. Electrocardiographic detection of left ventricular hypertrophy by the simple QRS voltageduration product. J Am Coll Cardiol 1992;20:1180-6.

10 Fagard RH, Staessen JA, Thijs L, et al. Prognostic significance of electrocardiographic voltages and their serial changes in elderly with systolic hypertension. Hypertension 2004;44:459-64.

11 Jain A, Tandri H, Dalal D, et al. Diagnostic and prognostic utility of electrocardiography for left ventricular hypertrophy defined by magnetic resonance imaging in relationship to ethnicity: the multi-ethnic study of atherosclerosis (MESA). Am Heart $J$ 2010;159:652-8.

12 Peguero JG, Lo Presti S, Perez J, et al. Electrocardiographic criteria for the diagnosis of left ventricular hypertrophy. J Am Coll Cardiol 2017;69:1694-703

13 Lang RM, Badano LP, Mor-Avi V, et al. Recommendations for cardiac chamber quantification by echocardiography in adults: an update from the American Society of echocardiography and the European association of cardiovascular imaging. Eur Heart $J$ Cardiovasc Imaging 2015;16:233-71.

14 Picard MH, Adams D, Bierig SM, et al. American Society of echocardiography recommendations for quality echocardiography laboratory operations. J Am Soc Echocardiogr 2011;24:1-10.

15 Devereux RB, Alonso DR, Lutas EM, et al. Echocardiographic assessment of left ventricular hypertrophy: comparison to necropsy findings. Am J Cardiol 1986;57:450-8.

16 de Simone G, Daniels SR, Devereux RB, et al. Left ventricular mass and body size in normotensive children and adults: assessment of allometric relations and impact of overweight. J Am Coll Cardiol 1992;20:1251-60.

17 DeLong ER, DeLong DM, Clarke-Pearson DL. Comparing the areas under two or more correlated receiver operating characteristic curves: a nonparametric approach. Biometrics 1988;44:837-45

18 Durrer D, van Dam RT, Freud GE, et al. Total excitation of the isolated human heart. Circulation 1970:41:899-912.

19 Chou TC, Helm RA, Kaplan S. Clinical vectorcardiography. 2nd ed. New York: Grune \& Stratton (New York), 1974: 71-84.

20 Reichek N, Devereux RB. Left ventricular hypertrophy: relationship of anatomic, echocardiographic and electrocardiographic findings. Circulation 1981;63:1391-8

21 Sliwa K, Wilkinson D, Hansen C, et al. Spectrum of heart disease and risk factors in a black urban population in South Africa (the heart of Soweto study): a cohort study. Lancet 2008;371:915-22.

22 Courand P-Y, Grandjean A, Charles P, et al. R wave in aVL lead is a robust index of left ventricular hypertrophy: a cardiac MRI study. Am $J$ Hypertens 2015;28:1038-48.

23 Courand P-Y, Gaudebout N, Mouly-Bertin C, et al. Biological, electrical and echocardiographic indices versus cardiac magnetic resonance imaging in diagnosing left ventricular hypertrophy. Hypertens Res 2014;37:444-51.

24 Morillas P, Castillo J, Quiles J, et al. Usefulness of NT-proBNP level for diagnosing left ventricular hypertrophy in hypertensive patients. A cardiac magnetic resonance study. Rev Esp Cardiol 2008;61:972-5.

25 Grandjean A, Courand P-Y, Mouly-Bertin C, et al. Risk stratification in hypertension: NT-proBNP and $\mathrm{R}$ wave in aVL lead combination better than echocardiographic left ventricular mass. $J$ Hypertens 2020;38:65-72.
26 Jayaraman S, Sangareddi V, Periyasamy R, et al. Modified limb lead ECG system effects on electrocardiographic wave amplitudes and frontal plane axis in sinus rhythm subjects. Anatol $J$ Cardiol 2017;17:46-54.

27 Mathew J, Sleight P, Lonn E, et al. Reduction of cardiovascular risk by regression of electrocardiographic markers of left ventricular hypertrophy by the angiotensin-converting enzyme inhibitor ramipril. Circulation 2001;104:1615-21.

28 Okin PM, Devereux RB, Jern S, et al. Regression of electrocardiographic left ventricular hypertrophy during antihypertensive treatment and the prediction of major cardiovascular events. JAMA 2004;292:2343-9.

29 Okin PM, Wachtell K, Devereux RB, et al. Regression of electrocardiographic left ventricular hypertrophy and decreased incidence of new-onset atrial fibrillation in patients with hypertension. JAMA 2006;296:1242-8.

30 Agarwal R, Song RJ, Vasan RS, et al. Left ventricular mass and incident chronic kidney disease. Hypertension 2020;75:702-6.

31 Aro AL, Chugh SS. Clinical diagnosis of electrical versus anatomic left ventricular hypertrophy: prognostic and therapeutic implications. Circ Arrhythm Electrophysiol 2016;9:e003629.

32 Bailey A, Korda R, Agostino J, et al. Absolute cardiovascular disease risk score and pharmacotherapy at the time of admission in patients presenting with acute coronary syndrome due to coronary artery disease in a single Australian tertiary centre: a cross-sectional study. BMJ Open 2021:11:e038868.

33 Gradman AH, Alfayoumi F. From left ventricular hypertrophy to congestive heart failure: management of hypertensive heart disease. Prog Cardiovasc Dis 2006;48:326-41.

34 Bauml MA, Underwood DA. Left ventricular hypertrophy: an overlooked cardiovascular risk factor. Cleve Clin J Med 2010;77:381-7.

35 de Hartog-Keyzer JML, El Messaoudi S, Harskamp R, et al. Electrocardiography for the detection of left ventricular hypertrophy in an elderly population with long-standing hypertension in primary care: a secondary analysis of the CHELLO cohort study. BMJ Open 2020;10:e038824.

36 Devereux RB, Wachtell K, Gerdts E, et al. Prognostic significance of left ventricular mass change during treatment of hypertension. JAMA 2004;292:2350-6.

37 Wagner DR, Heyward VH. Measures of body composition in blacks and whites: a comparative review. Am J Clin Nutr 2000;71:1392-402.

38 Sun G-Z, Wang H-Y, Ye N, et al. Assessment of novel Peguero-Lo Presti electrocardiographic left ventricular hypertrophy criteria in a large Asian population: newer may not be better. Can J Cardiol 2018;34:1153-7.

39 Dai S, Ayres NA, Harrist RB, et al. Validity of echocardiographic measurement in an epidemiological study. project heartbeat! Hypertension 1999;34:236-41.

40 Whelton PK, Carey RM, Aronow WS, et al. 2017 ACC/AHA/AAPA ABC/ACPM/AGS/APhA/ASH/ASPC/NMA/PCNA guideline for the prevention, detection, evaluation, and management of high blood pressure in adults: Executive summary: a report of the American College of Cardiology/American heart association Task force on clinical practice guidelines. Circulation 2018;138:e426-83.

41 de Lemos JA, Ayers CR, Levine BD, et al. Multimodality strategy for cardiovascular risk assessment: performance in 2 population-based cohorts. Circulation 2017;135:2119-32.

42 Bella JN, Devereux RB, Roman MJ, et al. Relations of left ventricular mass to fat-free and adipose body mass: the strong heart study. The strong heart study Investigators. Circulation 1998;98:2538-44.

43 Abergel E, Tase M, Bohlender J, et al. Which definition for echocardiographic left ventricular hypertrophy? Am J Cardiol 1995; 75:498-502.

44 Wachtell K, Bella JN, Liebson PR, et al. Impact of different partition values on prevalences of left ventricular hypertrophy and concentric geometry in a large hypertensive population : the LIFE study. Hypertension 2000;35:6-12.

45 de Simone G, Devereux RB, Daniels SR, et al. Effect of growth on variability of left ventricular mass: assessment of allometric signals in adults and children and their capacity to predict cardiovascular risk. J Am Coll Cardiol 1995;25:1056-62.

46 Liao Y, Cooper RS, Durazo-Arvizu R, et al. Prediction of mortality risk by different methods of indexation for left ventricular mass. J Am Coll Cardiol 1997;29:641-7. 